\title{
Mechanical coupling between the hemithoraces in humans
}

\author{
B. Johansen*, P. Giæver*, F. Aspestrand**, A. Kolbenstvedt**
}

Mechanical coupling between the hemithoraces in humans. B. Johansen, P. Giaver, F. Aspestrand, A. Kolbenstvedt. (C) ERS Journals Ltd 1996.

ABSTRACT: Unilateral airway occlusion permits measurement of single lung function. Since the results suggest that the occluded lung influences the mobility of the contralateral hemithorax, we wanted to test this hypothesis.

In eight healthy subjects, we measured, using computed tomography, lung parenchymal area and inner rib cage parasagittal and transverse diameters at three different levels and at maximal inspiration and expiration. These measurements were made without and during balloon occlusion of one mainstem bronchus at residual volume (RV) and at total lung capacity (TLC).

Unilateral occlusion at $\mathrm{RV}$ reduced the ipsilateral diameters in maximal inspiration, but the increase during inspiration was still $39-50 \%$ of that without occlusion. The inspiratory increase in contralateral diameters was reduced to $64-80 \%$ of the increase without occlusion. Occlusion at TLC reduced the expiratory decrease in ipsilateral diameters to $37-57 \%$ of that without occlusion. The expiratory decrease on the contralateral side was reduced to 56-70\% of that without occlusion. Due to accompanying mediastinal shifts the parenchymal areas of the occluded lung barely changed. In contrast, the contralateral area was $86-97 \%$ of that without occlusion.

We conclude that the movement of the two hemithoraces are, at least partially, interdependent. The occluded hemithorax prevents full expansion/compression of the nonoccluded contralateral side, whilst its own mobility appears to be increased by the presence of this nonoccluded side. Potential negative effects are outweighed by the physiological benefit of the coupling, as this mechanism could secure ventilation to a chest half without own movement.

Eur Respir J., 1996, 9, 140-145.

In two previous studies on healthy subjects, we occluded one mainstem bronchus with an inflatable balloon and measured the function of the other single lung. When one lung was occluded at total lung capacity (TLC), the other lung could not empty properly [1]. When it was occluded at residual volume (RV), the other lung could not expand fully [2]. These results indicate that the two lungs cannot be at opposite extreme volumes at the same time. The mobility of the rib cage is one of the factors that determine maximal filling and emptying of the lungs $[3,4]$. When one lung is occluded at RV or TLC, the hemithorax on that side cannot expand or compress properly. We wondered if the reduced mobility on the occluded side also limited the movement of the nonoccluded hemithorax. If so, this could explain our physiological finding.

The purpose of the present study was, therefore, to determine how occlusion of a single lung at RV and TLC affects the mobility of the chest wall, both on the occluded and the nonoccluded side.

\section{Subjects and methods}

\section{Subjects}

Eight healthy volunteers, six females and two males, aged 19-44 yrs, were studied. They had no history of
Depts of *Thoracic Medicine and ***Radiology, Rikshospitalet, The National Hospital, University of Oslo, Norway.

Correspondence: B. Johansen Dept of Thoracic Medicine Rikshospitalet

N-0027 Oslo

Norway

Keywords: Bronchoscopy catheters

computed tomography

lung volume

mediastinum

thorax

Received: August 41994

Accepted after revision July 111995

This work was financially supported by Glaxo Norway AS. respiratory or cardiac disease or recent airway infection. Their ventilatory lung function was within normal limits as determined by dynamic spirometry on the day of investigation [5]. One additional male was investigated but excluded due to failure of the inflated balloon to occlude the right mainstem bronchus. Each subject was informed carefully about the purpose and content of the study, both verbally and in writing. All gave written informed consent to participate. The study was approved by the Regional Health Area Ethics Committee.

\section{Study design}

This was an open within-subject comparative experiment. From computed tomography (CT) scans, lung parenchymal area and inner rib cage diameters of each hemithorax were measured in four different consecutive circumstances, randomly sequenced: maximal inspiration without and during unilateral occlusion of one mainstem bronchus at RV; and maximal expiration without and during occlusion of the same lung at TLC.

\section{Airway occlusion}

The mainstem bronchus was occluded by inflating the balloon of an $80 \mathrm{~cm}$ long Fogarty venous thrombectomy catheter, size 8/10 French (American Edwards Laboratories, 
Santa Ana, Ca, USA). The balloon had a maximum diameter of $19 \mathrm{~mm}$ and a maximum capacity of $4 \mathrm{~mL}$ fluid. The catheter was advanced transnasally into the mainstem bronchus under guidance of a fibreoptic bronchoscope (Olympus BF OC10) during topical anaesthesia with nebulized oxybuprocaine. The subjects were premedicated with atropine, diazepam and hydro-codone. Other details of the insertion procedure, including safety aspects, were as described in a previous paper [1].

With the deflated balloon in one mainstem bronchus, the seated subject either inhaled or exhaled maximally and held their breath. The balloon was then inflated rapidly with saline until it completely occluded the airway. The position of the balloon was checked during one or two tidal breaths before deflation. The inflation/deflation procedure was repeated, if necessary, to adjust the position of the balloon and the volume of instilled saline. The catheter with deflated balloon was then fixed to the nostril, the bronchoscope removed and the subjects placed on the $\mathrm{CT}$ table in the supine position. During a VC manoeuvre, the nose/carina distance varies within approximately $1 \mathrm{~cm}$. A change in posture from sitting to supine affects this distance appreciably less. The volume-induced change in distance poses no problem in the long left mainstem bronchus. In contrast, to be certain that the balloon was inflated in the right mainstem bronchus (four subjects), the nasal fixation point of the catheter had to be adjusted when occlusion volume was changed from one to the other.

\section{Thoracic CT scans}

Rib cage dimensions were assessed with a CT-T-9800 (General Electric, Milwaukee, WI, USA) and with standard algorithms. Matrix size was $256 \times 256$ and scan time $2 \mathrm{~s}$. Four series of transverse images were exposed: 1) at maximal inspiration with deflated balloon; 2) at maximal expiration with deflated balloon; 3 ) at maximal inspiration just after occlusion of one mainstem bronchus at maximal expiration; 4) at maximal expiration just after occlusion of the same bronchus in maximal inspiration. Immediately before exposure, the subjects performed two or three tidal breaths before they inhaled or exhaled completely. Each series consisted of three sections, each 5 $\mathrm{mm}$ thick and $2 \mathrm{~cm}$ apart. The level of the most cranial (upper) section was determined in maximal inspiration without occlusion and corresponded to the carina. One series was completed in $11 \mathrm{~s}$, during which time the subjects held their breath in maximal inspiration or expiration. Lung volume was not controlled during breathholding. The subjects were not allowed to move on the table between series. The balloon was never inflated more than $30 \mathrm{~s}$ at a time and was always deflated between each series. Arterial oxygen saturation was recorded throughout the procedure with a pulse oximeter (Minolta Pulsox7 ), and remained well above $90 \%$ in all subjects.

\section{Variables}

From each section, 12 in total for each subject, the maximum right and left inner parasagittal diameter, right and left transverse diameter, the mediastinal shift, and the right and left parenchymal area were measured. Figure 1

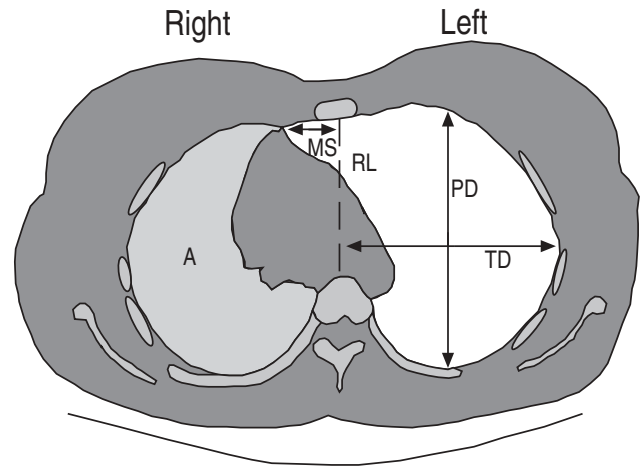

Fig. 1. - Redrawing of the computed tomography scan of the upper thoracic section of subject No. 6, viewed from beneath, at maximal inspiration during occlusion of the right lung at residual volume. PD: parasagittal diameter; TD: transverse diameter; RL: reference line; MS: mediastinal shift; A: area. Note the smaller dimensions on the right side (arrows not drawn) as compared to the left.

shows a redrawing of one section and the variables measured. The variables were calculated as the distance between two measuring points, moveable on the monitor with a track-ball. The inner parasagittal diameter was measured on the monitor along a sagittal line from the most posterior position of the pleura. The transverse diameter of one hemithorax was measured along a horizontal line from the most lateral point of the pleura to a vertical line through the centre of the vertebra. The latter line served as the reference line for the mediastinum. The mediastinal shift was taken as the distance that the posterior connecting point of the anterior junction line moved away from the reference line. The area of each lung section was calculated as the sum of all pixels with attenuation value less than minus 200 Hounsfield units (HU) within each hemithorax. The medial border of one hemithoracic area was defined by the mediastinum, irrespective of its position.

The lung with the balloon was the ipsilateral lung. An index of symmetry of the ipsilateral and contralateral hemithorax due to occlusion was calculated as follows. Firstly, the observed increase in the parasagittal diameter from maximal expiration to maximal inspiration during occlusion was expressed as a fraction of the expected increase, i.e. the increase without occlusion. Secondly, when this fraction was computed for both hemithoraces, the ratio of the ipsilateral to the contralateral fraction was taken as a measure of symmetry in full inspiration during occlusion of one lung at RV. An index of symmetry in full expiration during occlusion of the same lung at TLC was calculated in the same way.

\section{Randomization and statistics}

In four subjects the right lung was occluded, and in the other four the left. The side to be occluded and the sequence of series were randomized for each subject according to a duplicated balanced latin square design. Statistical Package for the Social Sciences (SPSS, version 4.0) was used for the data entry and analysis. Mean values were compared by the two-tailed paired t-test and considered to be significantly different if the p-value was less than 0.05 . 


\section{Results}

\section{Effect of occlusion on the contralateral hemithorax}

The parasagittal and transverse diameters of all contralateral sections were significantly reduced in maximal inspiration when the ipsilateral lung was occluded at RV (table 1). Compared to the inspiratory increase without occlusion, these diameters increased $80 \%$ or less during occlusion. The effect of occlusion on the contralateral area was smaller, but still significant in the upper two sections.
When the ipsilateral lung was occluded at TLC (expiratory occlusion), the contralateral diameters were significantly larger in maximal expiration than they were without ipsilateral occlusion (table 2). Again, the effect of expiratory occlusion on area was small and not significant in the lower section.

\section{Effect of occlusion on the ipsilateral hemithorax}

Table 3 shows that all ipsilateral dimensions were significantly decreased in maximal inspiration when this lung was occluded at RV. Similarly, during expiration,

Table 1. - Contralateral hemithoracic dimensions in maximal inspiration without occlusion and during ipsilateral occlusion at RV in eight healthy subjects

\begin{tabular}{|c|c|c|c|c|c|c|}
\hline \multirow[t]{2}{*}{ Variable } & \multicolumn{3}{|c|}{ Contralateral section } & \multirow{2}{*}{$\begin{array}{c}\text { Increase* } \\
(\% \text { expected })\end{array}$} & \multirow[t]{2}{*}{ SED } & \multirow[t]{2}{*}{ p-value } \\
\hline & & Jo occlusion & $\begin{array}{c}\text { Ipsilateral occlusion } \\
\text { at RV }\end{array}$ & & & \\
\hline \multirow[t]{3}{*}{ Parasagittal diameter $\mathrm{cm}$} & Upper & $\begin{array}{l}15.3 \\
(0.33)\end{array}$ & $\begin{array}{l}13.6 \\
(0.30)\end{array}$ & 64 & 0.21 & $<0.001$ \\
\hline & Middle & $\begin{array}{l}16.2 \\
(0.28)\end{array}$ & $\begin{array}{l}14.8 \\
(0.24)\end{array}$ & 67 & 0.18 & $<0.001$ \\
\hline & Lower & $\begin{array}{l}16.8 \\
(0.24)\end{array}$ & $\begin{array}{l}15.6 \\
(0.24)\end{array}$ & 70 & 0.19 & $<0.001$ \\
\hline \multirow[t]{3}{*}{ Transverse diameter $\mathrm{cm}$} & Upper & $\begin{array}{l}12.1 \\
(0.27)\end{array}$ & $\begin{array}{l}11.9 \\
(0.21)\end{array}$ & 80 & 0.11 & $<0.05$ \\
\hline & Middle & $\begin{array}{l}12.7 \\
(0.25)\end{array}$ & $\begin{array}{l}12.3 \\
(0.23)\end{array}$ & 65 & 0.07 & $<0.001$ \\
\hline & Lower & $\begin{array}{l}12.8 \\
(0.25)\end{array}$ & $\begin{array}{l}12.3 \\
(0.23)\end{array}$ & 71 & 0.07 & $<0.01$ \\
\hline \multirow[t]{3}{*}{ Area $\mathrm{cm}^{2}$} & Upper & $\begin{array}{r}131.4 \\
(5.8)\end{array}$ & $\begin{array}{r}122.3 \\
(5.2)\end{array}$ & 87 & 2.69 & $<0.05$ \\
\hline & Middle & $\begin{array}{r}137.1 \\
(7.4)\end{array}$ & $\begin{array}{r}131.8 \\
(7.9)\end{array}$ & 93 & 2.18 & $<0.05$ \\
\hline & Lower & $\begin{array}{l}139.8 \\
(7.9)\end{array}$ & $\begin{array}{r}137.0 \\
(7.9)\end{array}$ & 97 & 2.19 & $>0.20$ \\
\hline
\end{tabular}

Values are presented as mean, and SEM in parenthesis. *: The increase is expressed as a $\%$ of expected. SED: standard error of the difference between means; RV: residual volume.

Table 2. - Contralateral hemithoracic dimensions in maximal expiration without occlusion and during ipsilateral occlusion at TLC in eight healthy subjects

\begin{tabular}{|c|c|c|c|c|c|c|}
\hline \multirow[t]{2}{*}{ Variable } & \multicolumn{3}{|c|}{ Contralateral section } & \multirow{2}{*}{$\begin{array}{l}\text { Decrease* } \\
(\% \text { expected })\end{array}$} & \multirow[t]{2}{*}{ SED } & \multirow[t]{2}{*}{$\mathrm{p}$-value } \\
\hline & & No occlusion & $\begin{array}{l}\text { Ipsilateral occlusion } \\
\text { at TLC }\end{array}$ & & & \\
\hline \multirow[t]{3}{*}{ Parasagittal diameter $\mathrm{cm}$} & Upper & $\begin{array}{l}10.8 \\
(0.35)\end{array}$ & $\begin{array}{l}12.7 \\
(0.45)\end{array}$ & 56 & 0.24 & $<0.001$ \\
\hline & Middle & $\begin{array}{l}12.1 \\
(0.32)\end{array}$ & $\begin{array}{l}13.8 \\
(0.40)\end{array}$ & 56 & 0.24 & $<0.001$ \\
\hline & Lower & $\begin{array}{l}12.9 \\
(0.26)\end{array}$ & $\begin{array}{l}14.6 \\
(0.28)\end{array}$ & 56 & 0.20 & $<0.001$ \\
\hline \multirow[t]{3}{*}{ Transverse diameter $\mathrm{cm}$} & Upper & $\begin{array}{l}10.9 \\
(0.25)\end{array}$ & $\begin{array}{l}11.3 \\
(0.23)\end{array}$ & 61 & 0.09 & $<0.01$ \\
\hline & Middle & $\begin{array}{l}11.4 \\
(0.21)\end{array}$ & $\begin{array}{l}11.8 \\
(0.23)\end{array}$ & 67 & 0.09 & $<0.01$ \\
\hline & Lower & $\begin{array}{l}11.8 \\
(0.25)\end{array}$ & $\begin{array}{l}12.1 \\
(0.24)\end{array}$ & 70 & 0.06 & $<0.001$ \\
\hline \multirow[t]{3}{*}{ Area $\mathrm{cm}^{2}$} & Upper & $\begin{array}{l}63.6 \\
(4.6)\end{array}$ & $\begin{array}{l}73.3 \\
(5.1)\end{array}$ & 86 & 2.42 & $<0.01$ \\
\hline & Middle & $\begin{array}{l}72.9 \\
(6.2)\end{array}$ & $\begin{array}{l}78.7 \\
(6.2)\end{array}$ & 91 & 2.01 & $<0.05$ \\
\hline & Lower & $\begin{array}{l}76.7 \\
(7.2)\end{array}$ & $\begin{array}{l}78.5 \\
(6.4)\end{array}$ & 97 & 1.76 & $>0.30$ \\
\hline
\end{tabular}

Values are presented as mean, and SEM in parenthesis. *: identical to expected increase in table 1. TLC: total lung capacity; SED: standard error of the difference between means. 
the ipsilateral lung did not reach its minimal size when it was occluded at TLC (table 4).

Occlusion of one bronchus did not prevent the ipsilateral hemithorax from changing its dimensions. Both the parasagittal and transverse diameters increased significantly during inspiration (compare occluded ipsilateral inspiratory dimensions (table 3) with nonoccluded expiratory dimensions (table 4)) and decreased significantly during expiration (compare nonoccluded ipsilateral inspiratory dimensions (table 3 ) with occluded expiratory dimensions (table4)) $(\mathrm{p}<0.01$ for all). The area of the ipsilateral lung parenchyma, however, did not change, except in the upper section, where it was $10 \%$ smaller during expiratory occlusion (table 4$)$ than in inspiration without occlusion (table 3$)(\mathrm{p}<0.01)$.

\section{Asymmetry due to occlusion}

The smaller increase in ipsilateral than in contralateral parasagittal diameter during inspiratory occlusion (tables 1 and 3, column 5) resulted in chest asymmetry. The inspiratory symmetry index (ipsilateral/contralateral ratio of the change in dimension as \% expected) was $0.67,0.58$ and 0.59 for the upper, middle and lower section, respectively. Expiratory occlusion also led to asymmetry (table 2 and 4, column 5) with symmetry indices of $0.80,0.74$ and 0.71 , respectively. All symmetry indices were significantly different from $1(\mathrm{p}<0.001)$. The difference between inspiratory and expiratory indices was significant for the middle section only $(\mathrm{p}<0.05)$.

The mediastinum shifted towards the deflated occluded

Table 3. - Ipsilateral hemithoracic dimensions in maximal inspiration without occlusion and during ipsilateral occlusion at RV in eight healthy subjects

\begin{tabular}{|c|c|c|c|c|c|c|}
\hline \multirow[t]{2}{*}{ Variable } & & \multicolumn{2}{|c|}{ Ipsilateral section } & \multirow{2}{*}{$\begin{array}{c}\text { Increase* } \\
(\% \text { expected })\end{array}$} & \multirow[t]{2}{*}{ SED } & \multirow[t]{2}{*}{ p-value } \\
\hline & & No occlusion & Occlusion at TLC & & & \\
\hline \multirow[t]{3}{*}{ Parasagittal diameter $\mathrm{cm}$} & Upper & $\begin{array}{l}14.8 \\
(0.24)\end{array}$ & $\begin{array}{l}12.2 \\
(0.23)\end{array}$ & 44 & 0.24 & $<0.001$ \\
\hline & Middle & $\begin{array}{l}15.9 \\
(0.17)\end{array}$ & $\begin{array}{l}13.2 \\
(0.24)\end{array}$ & 39 & 0.24 & $<0.001$ \\
\hline & Lower & $\begin{array}{l}16.4 \\
(0.21)\end{array}$ & $\begin{array}{l}14.1 \\
(0.23)\end{array}$ & 41 & 0.23 & $<0.001$ \\
\hline \multirow[t]{3}{*}{ Transverse diameter $\mathrm{cm}$} & Upper & $\begin{array}{l}12.2 \\
(0.26)\end{array}$ & $\begin{array}{l}11.6 \\
(0.28)\end{array}$ & 45 & 0.07 & $<0.001$ \\
\hline & Middle & $\begin{array}{l}12.5 \\
(0.31)\end{array}$ & $\begin{array}{l}11.9 \\
(0.31)\end{array}$ & 42 & 0.11 & $<0.01$ \\
\hline & Lower & $\begin{array}{l}12.7 \\
(0.32)\end{array}$ & $\begin{array}{l}12.2 \\
(0.31)\end{array}$ & 50 & 0.11 & $<0.01$ \\
\hline \multirow[t]{3}{*}{ Area $\mathrm{cm}^{2}$} & Upper & $\begin{array}{r}129.9 \\
(4.5)\end{array}$ & $\begin{array}{l}68.1 \\
(2.3)\end{array}$ & 5 & 3.43 & $<0.001$ \\
\hline & Middle & $\begin{array}{r}137.3 \\
(5.6)\end{array}$ & $\begin{array}{l}72.5 \\
(2.1)\end{array}$ & 2 & 4.53 & $<0.001$ \\
\hline & Lower & $\begin{array}{r}139.8 \\
(6.8)\end{array}$ & $\begin{array}{l}77.8 \\
(2.5)\end{array}$ & 0 & 4.97 & $<0.001$ \\
\hline
\end{tabular}

Values are presented as mean, and SEM in parenthesis. *: the expected increase. For abbreviations see legend to table 1.

Table 4. - Ipsilateral hemithoracic dimensions in maximal expiration without occlusion and during ipsilateral occlusion at TLC in eight healthy subjects

\begin{tabular}{|c|c|c|c|c|c|c|}
\hline \multirow[t]{2}{*}{ Variable } & & \multicolumn{2}{|c|}{ Ipsilateral section } & \multirow{2}{*}{$\begin{array}{c}\text { Decrease* } \\
(\% \text { expected })\end{array}$} & \multirow[t]{2}{*}{ SED } & \multirow[t]{2}{*}{$\mathrm{p}$-value } \\
\hline & & No occlusion & Occlusion at TLC & & & \\
\hline \multirow[t]{3}{*}{ Parasagittal diameter $\mathrm{cm}$} & Upper & $\begin{array}{l}10.2 \\
(0.29)\end{array}$ & $\begin{array}{l}12.8 \\
(0.37)\end{array}$ & 45 & 0.38 & $<0.001$ \\
\hline & Middle & $\begin{array}{l}11.5 \\
(0.21)\end{array}$ & $\begin{array}{l}14.1 \\
(0.36)\end{array}$ & 41 & 0.29 & $<0.001$ \\
\hline & Lower & $\begin{array}{l}12.4 \\
(0.24)\end{array}$ & $\begin{array}{l}14.9 \\
(0.27)\end{array}$ & 37 & 0.25 & $<0.001$ \\
\hline \multirow[t]{3}{*}{ Transverse diameter $\mathrm{cm}$} & Upper & $\begin{array}{l}11.1 \\
(0.26)\end{array}$ & $\begin{array}{l}11.5 \\
(0.22)\end{array}$ & 57 & 0.07 & $<0.001$ \\
\hline & Middle & $\begin{array}{l}11.5 \\
(0.28)\end{array}$ & $\begin{array}{l}12.0 \\
(0.26)\end{array}$ & 47 & 0.08 & $<0.001$ \\
\hline & Lower & $\begin{array}{l}11.7 \\
(0.28)\end{array}$ & $\begin{array}{l}12.2 \\
(0.23)\end{array}$ & 43 & 0.10 & $<0.001$ \\
\hline \multirow[t]{3}{*}{ Area $\mathrm{cm}^{2}$} & Upper & 64.2 & 118.2 & 17 & 3.62 & $<0.001$ \\
\hline & Middle & $\begin{array}{l}70.9 \\
(2.3)\end{array}$ & $\begin{array}{l}131.8 \\
(4.2)\end{array}$ & 7 & 4.42 & $<0.001$ \\
\hline & Lower & $\begin{array}{l}78.0 \\
(3.5)\end{array}$ & $\begin{aligned} 142.0 \\
(4.4)\end{aligned}$ & -7 & 3.85 & $<0.001$ \\
\hline
\end{tabular}

Values are presented as mean, and SEM in parenthesis. *: identical to expected increase in table 3. For abbreviations see legend to table 2 . 
lung during inspiration. The displacement was 2.7, 3.1 and $3.5 \mathrm{~cm}$ in the upper, middle and lower section, respectively. During expiratory occlusion, it moved in the opposite direction, 2.8, 2.9 and $3.3 \mathrm{~cm}$, respectively. The increase in the caudal direction was not statistically significant.

\section{Discussion}

This study has shown that limited expansion and compression of one hemithorax, due to occlusion of its main bronchus, are accompanied by reduced inspiratory and expiratory movement of the other hemithorax as well. The limiting effect that occlusion had was largest on the ipsilateral side and led to chest wall asymmetry. However, the movements on that side were larger than expected. On the nonoccluded side, the increase in diameters during inspiration was less than $80 \%$ of expected, and the decrease during expiration less than $70 \%$ of expected. Due to compensatory mediastinal shifts, occlusion had a much smaller effect on the nonoccluded parenchymal area than on the rib cage diameters on this side. These results indicate that the hemithoraces are neither completely interdependent, nor completely independent. The independence is shown by the asymmetry, the interdependence by the fact that the nonoccluded hemithorax is halted in its movement whilst that on the occluded side is facilitated.

In anaesthetized dogs, inspiratory occlusion of the trachea leads to decreased activity of some inspiratory muscles (parasternal intercostals), and increased activity of others (external intercostals and levator costae) [6]. Although similar mechanisms may have influenced the results, we believe that our findings are best explained by mechanical coupling between the two chest halves. The upper ribs, in particular the first, are firmly attached to the sternum [7] and are highly resistant to loads in the superior and inferior direction [8]. The movement of the first costovertebral joint is also limited, and the first costal ring (the manubrium sterni, the first rib and first vertebra) therefore moves as a rigid body [9]. The sternum changes its position markedly in the sagittal plane, the upper spine to a lesser degree, during a full inspiratory manoeuvre [9]. If the displacement of these structures is prevented on one side due to an occluded lung, it is likely that the rigidity of the first costal ring also arrests the movement of the other hemithorax. In dogs, experiments have indicated that the sternum and upper ribs move as one anatomical unit [10].

Distortion of the rib cage may have contributed to the reduced contralateral parasagittal diameters during inspiratory occlusion. Increased inspiratory load has been shown to decrease the sagittal and increase the transverse diameter [11]. However, distortion seems to be dependent on thoracic volume. At high lung volumes, the anteroposterior diameter increases rather than decreases [12]. Our experimental design makes it difficult to quantify thoracic volume during inspiratory occlusion, but it was probably "high" on the contralateral side. The fact that the contralateral transverse diameters also decreased makes it unlikely that distortion contributed much to the results. The upper section was always taken first and the lower last. We cannot rule out the possibility that the rib cage changed its configuration in maximal inspiration during the $11 \mathrm{~s}$ it took to complete one series [11], and that the upper diameters were hence underestimated.

Another possible measurement artifact may explain why the 12 upper sections, which had the smallest parasagittal diameter, increased most during a normal inspiration. The upper section was preset to the carinal level in full inspiration without occlusion, regardless of the subsequent caudal movement of the conical rib cage [9]. Due to the curved shape of the thorax in its upper part, the uppermost section would change its diameter more than the others when moving up and down. However, although the distances between the sections were small, the different direction of the rotating axis of the rib necks at different levels also explains why the upper part increased the most in the sagittal plane [13].

The upper contralateral section was also the one that was inhibited most during inspiratory occlusion. Again, this could be explained by the conical and curved rib cage. On the other hand, the larger effect on the uppermost section is also in agreement with the concept of a rigid first costal ring [9]. The ribs that were farther away from the first ring were obviously less influenced by the latter and could expand more freely. Moreover, the decreases in ipsilateral parasagittal diameters were independent of section, suggesting that the shape of the rib cage did not contribute to the reduced diameters on that side. Finally, the larger symmetry in the upper compared to the lower section, although not significantly different, is also in agreement with the concept of a rigid first costal ring. Due to the shift of the mediastinum, the nonoccluded parenchymal area was less affected than the diameters on that side. The mediastinum obviously acted as a buffer during occlusion and compensated for the reduced movement of the bony structures. The compensation was complete in the lower section, which was unaffected by occlusion.

The findings in the present study are in agreement with previous physiological studies, in which occlusion of one lung at TLC led to a small but significant increase in $\mathrm{RV}$ of the other lung [1], whilst unilateral occlusion at RV led to a decreased TLC of the other lung [2]. The compensatory effect that the mediastinal shift had on lung area in this study explains why the previously observed differences in lung volumes with and without occlusion were small compared to the large difference in the linear dimensions observed here.

Ideally, we should have measured the hemidiaphragmatic displacements during occlusion. This might have shown whether the third linear dimension of the rib cage was reduced, not only on the occluded side (where it was expected), but also on the nonoccluded side. Theoretically, however, the altered abdominal pressure caused by the reduced displacement on the occluded side could have led to a normal or even supernormal hemidiaphragmatic displacement on the other side. If the latter is the case, the reduced sagittal rib cage expansion on the nonoccluded side is buffered both by mediastinal shift and by overextension of the hemidiaphragm on that side. 
Patients with hemithoracic disorders, unilateral lung disease or single lung transplants could be regarded as having a functional occlusion of one lung. After single lung transplantation for pulmonary emphysema, the significant increase in forced expiratory volume in one second (FEV1) from 20 to $55 \%$ of predicted was accompanied by an insignificant increase in vital capacity (VC) from 50 to $56 \%$ of predicted [14]. This suggests that the native hyperinflated hemithorax prevented the new lung from emptying properly. Similarly, after single lung transplantation for pulmonary fibrosis [15], the average $\mathrm{VC}$ rose from 43 to $69 \%$ and (FEV1) from 50 to $79 \%$ of predicted. If we assume that the average postoperative contribution of the remaining native lung was still 22 and $25 \%$ of the predicted $\mathrm{VC}$ and $\mathrm{FEV} 1$, the average contribution of the new lung was $47 \%$ of the predicted VC compared to $54 \%$ of the predicted FEV1. This suggests that the new lung was hindered from expanding fully. The effect of thoracotomy itself on VC [16] was probably negligible in these studies.

In spite of being occluded, the ipsilateral hemithorax increased its diameter by approximately $40 \%$ of what was possible. According to published volume-motion coefficients for the supine rib cage [17], the corresponding increase in lung volume is $25 \%$ of the vital capacity. This is far more than the change in thoracic volume measured in a body plethysmograph during forceful panting against the shutter [18]. It therefore appears as if the occluded hemithorax was helped in its expansion by its nonoccluded partner, but at the expense of the latter's own movement. The mechanical coupling between the two may be of importance in hemiplegic subjects, in whom the ipsilateral respiratory muscles are severely affected [19]. During voluntary deep ventilation, the maximal external sagittal diameter of the hemiplegic chest wall was $90 \%$ of that on the healthy side [20]. In the present study, the mean ipsilateral parasagittal diameter during inspiratory occlusion was $84 \%$ of that without occlusion. The small difference can be explained by different measuring techniques and the presumably higher negative pressure in the occluded hemithorax in the present study.

We conclude that reduced mobility of one chest half limits that of the other as well. Conversely, and more importantly, the more mobile nonoccluded chest half appears to help to increase the movement on the occluded side. The coupling between the chest halves is most likely caused by the rigidity of the uppermost part of the thorax. The negative effects are probably of little clinical relevance. The positive effect of the coupling is physiologically more important as this mechanism apparently secures ventilation to a chest half that is unable to move by its own.

Acknowledgements: The valuable technical assistance from E-M. Blix, I. Hem, G. Leikvoll and S.A. Tutt is highly appreciated.

\section{References}

1. Johansen B, Bjørtuft $\varnothing$, Boe J. Static lung volumes in healthy subjects assessed by helium dilution during occlusion of one mainstem bronchus. Thorax 1993; 48: 381-384.

2. Johansen B, Bjørtuft. Single lung alveolar volume and gas transfer: effect of expansion of the other lung. Thorax 1994: 49; 1238-1242.

3. Feltelius N, Hedenstrom H, Hillerdal G, Hallgren R. Pulmonary involvement in ankylosing spondylitis. Ann Rheum Dis 1986; 45: 736-740.

4. Leith DE, Mead J. Mechanisms determining residual volume of the lungs in normal subjects. J Appl Physiol 1967; 23: 221-227.

5. Quanjer PH (ed). Standardized lung function testing. Clin Respir Physiol 1983; 19 (Suppl. 5): 45-51.

6. De Troyer A. Differential control of the inspiratory intercostal muscles during airway occlusion in the dog. $J$ Physiol 1991; 439: 73-88.

7. Gray's Anatomy. In: Williams PL, Warwick R, Dyson M, Bannister LH, eds. Edinburgh, Churchill Livingstone, 1989; pp. 497-498.

8. Schultz A, Benson D, Hirsch C. Force-deformation properties of human costosternal and costovertebral articulations. J Bio mech 1974; 7: 311-318.

9. Saumarez RC. An analysis of possible movements of human upper rib cage. J Appl Physiol 1986; 60: 678689.

10. De Troyer A, Decramer M. Mechanical coupling between the ribs and sternum in the dog. Respir Physiol 1985; 59: 27-34.

11. Agostoni E, Mognoni P. Deformation of the chest wall during breathing efforts. J Appl Physiol 1966; 21: 18271832.

12. Saunders NA, Kreitzer SM, Ingram RH Jr. Rib cage deformation during static inspiratory efforts. J Appl Physiol 1979; 46: 1071-1075.

13. Jordanoglou J. Rib movement in health, kyphoscoliosis and ankylosing spondylitis. Thorax 1969; 24: 407-414.

14. Patterson GA, Maurer JR, Williams TJ, et al Comparison of outcomes of double- and single-lung transplantation for obstructive lung disease. J Thorac Cardiovasc Surg 1991; 101: 623-632.

15. Grossman RF, Frost A, Zamel N, Patterson GA, et al. Results of single-lung transplantation for bilateral pulmonary fibrosis. N Engl J Med 1990; 322: 727-733.

16. Gorlin R, Knowles JH, Storey FC. Effects of thoracotomy on pulmonary function. J Thorac Surg 1957; 34: 242-249.

17. Konno K, Mead J. Measurement of the separate volume changes of rib cage and abdomen during breathing. $J$ Appl Physiol 1967; 22: 407-422.

18. DuBois AB, Botelho SY, Bedell GN, Marshall R, Comroe JH Jr. A rapid plethysmographic method for measuring thoracic gas volume. J Clin Invest 1956; 35: 322 326.

19. De Troyer A, Zegers de Beyl D, Thirion M. Function of the respiratory muscles in acute hemiplegia. Am Rev Respir Dis 1981; 123: 631-632.

20. Fluck DC. Chest movements in hemiplegia. Clin Sci 1966; 31: 383-388. 